\title{
CS intensity as a function of the experimental design'
}

LAIRD S. CERMAK OHIO STATE UNIVERSITY

The purpose of this experiment was to compare stimulus intensity effects using a GSR measure in the context of both a Between $S$ s and a Within Ss experimental design. Two transformation formulas were utilized and both resulted in essentially the same behavioral outcome. Results showed a significant Within Ss intensity effect, but no difference $\mathrm{B} e$ tween Ss.

Beck (1963) and Grice \& Hunter (1964), employing eyeblink techniques and comparing a between-Ss design and a within-Ss design, obtained results which demonstrated a signiffcant CS intensity effect within, but not between, Ss. Previous to this report the majority of studies concerning stimulus intensity effects obtained negative results which Gray (1965) attempted to explain as being caused by the use of extinction measures and the frequent utilization of the GSR.

The purpose of this experiment is to investigate the stimulus intensity effects in a GSP conditioning situation employing both between-Ss and within-Ss experimental designs as Grice and Hunter employed in their eyeblink experiment.

Method

Forty Ss from introductory psychology courses at The Ohio State University were assigned at random to the Between-Ss groups (20 for each intensity) and 20 to the Within-Ss group. Each $S$ was seated in a chair and the shock and GSR electrodes were attached. A standard set of instructions to familiarize Ss was given. Following six tone adaptation trials to the 40 and $80 \mathrm{~dB}$ (re: .0002 dynes $/ \mathrm{cm}^{2}$ ) stimuli, and three shock adaptation trials, CS-UCS pairings began. Twenty-four acquisition trials followed, 16 reinforced and eight interspersed, nonreinforced test trials. Ten extinction trials followed the acquisition series. For the Within-Ss group, the intensities were randomly presented with the stipulation that no intensity occur more than twice in a row. Counterbalancing for trial effects was used. During acquisition and extinction the CS duration was 600 msec. The interval between CS onset and UCS onset was $500 \mathrm{msec}$ and UCS duration was 100 msec. Responses were recorded on all trials visually from a Fels Dermohmeter and checked against an Esterline Angus recording.

Results

Transformations. Two transformation methods were used. The most frequently cited, based on a log conductance scale $(\log ((1 / \mathrm{Ra}-1 / \mathrm{Rb})+1))$ was proposed by Darrow (1937). Recently, Montagu \& Coles (1966) have expressed the GSR scale of the "change" In $\log$ conductance or in equation form: $\log \left(1 / \operatorname{Ra} \times 10^{6}\right)$ $-\log \left(1 / \mathrm{Rb} 1^{6}\right)$, which reduces to the $\log (\mathrm{Rb} / \mathrm{Ra})$. Montagu and Coles point out that it is imperative to note the difference between " $\mathrm{log}$ change in conductance" and "change in log conductance" as the two are readily confused. However, only the complete analysis for the second transformation will be presented here since transformations resulted in the same behavioral and statistical outcomes.

Acquisition. Figure 1 shows the acquisition data utilizing the mean change in log conductance transformation. The single-stimulus (Between-Ss) condithon is not significant $(t=0,48, d f=38)$. The two-stimulus condition is significant $(F=21.65, \mathrm{df}=1 / 19, \mathrm{p}<.001)$. The soft tone is significantly greater for the singlestimulus condition $(t=1.76, \mathrm{df}=38, \mathrm{p}<.05)$, but not for the loud tone $(80 \mathrm{~dB})(t=0.36, \mathrm{df}=38)$.

Extinction. Figure 2 shows the mean change in log conductance during the extinction series. The singlestimulus condition is not significant $(t=0.52$, $d f=38)$. The two-stimulus condition is significant ( $F=21.14$, $\mathrm{df}=1 / 19, p<.001)$. Neither the soft tone $(t=0.71$, df

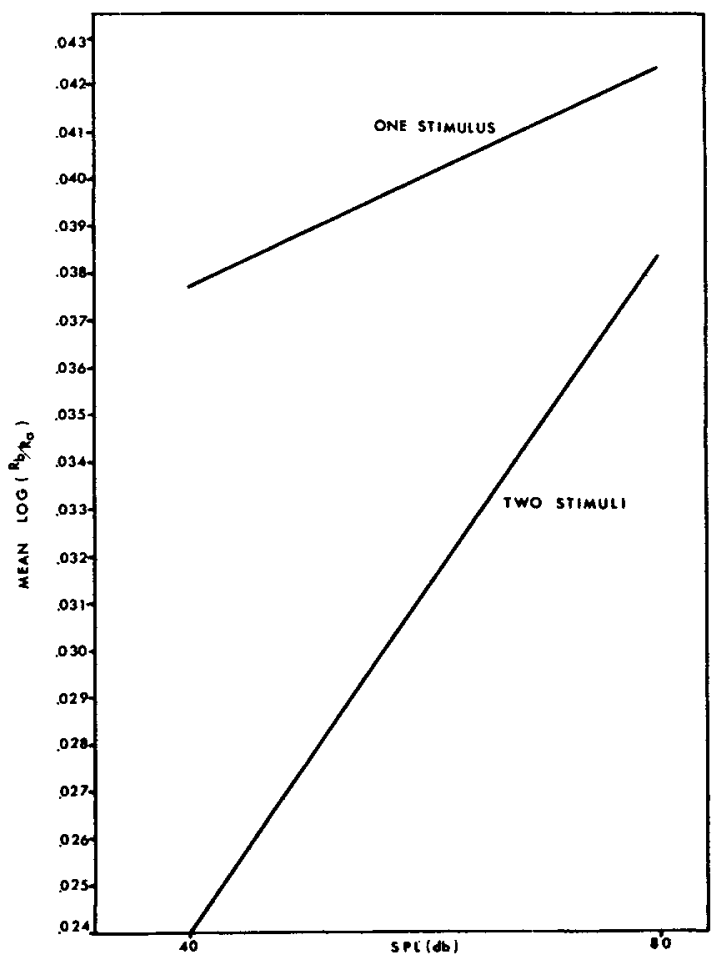

Fig. 1. Mean GSR based on eight test trials during acquisition. 


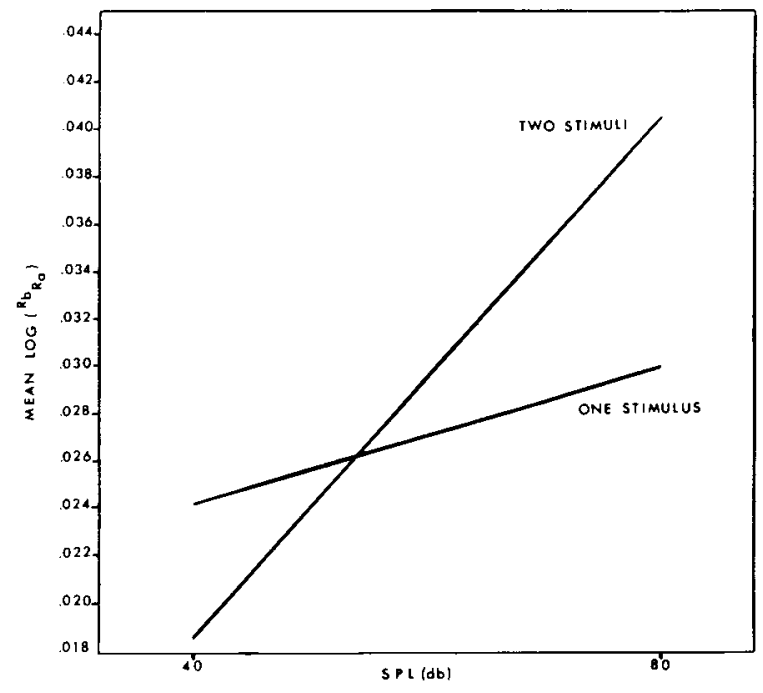

Fig. 2. Mean GSR based on 10 extinction trials.

$=38$ ) nor loud tone $(t=0.82, d f=38)$ differences were significant.

Dividing the Within-Ss group and performing interaction tests as developed by Grice and Hunter it was found that only the extinction data using the mean log change in conductance achieved significance $(F=4.48$, df $=1 / 38, p<.05$ ). In all other cases the two transformations obtained the same results.

Discussion

Statistically, the utilization of a Within-Ss experimental design results in a smaller error term than its comparable Between-Ss design. This experiment has shown that the use of this experimental design can also result in different "behavioral" effects. Previously, the CS in a GSR conditioning experiment was thought to be merely a "signal" for the impending onset of a dominating UCS, the shock. This has repeatedly been demonstrated in experiments in which Ss experienced one and only one CS intensity. This effect was also replicated here, as shown by the single-stimulus condition.

If, however, two different intensities of a stimulus are both presented to the same $S$, a different behavioral effect is produced. The stimulus intensity shows itself as a dynamism, "energizing" or orienting effect. Thus, intensity effects are not determined solely by the specific stimulus characteristics, but by an interaction of the combinations of CS characteristics involved.

An interesting effect can be observed from Fig. 1. During acquisition the response to the $80 \mathrm{~dB}$ intensity in the two-stimulus condition shows no significant difference from either single-stimulus condition. The $40 \mathrm{~dB}$ intensity does show a significantly inhibited effect. It appears that the response to a signal for the onset of a UCS is maximized for any single-stimulus condition. In the two-stimulus condition it is inhibited to the less intense CS.

Then, during extinction (Fig. 2), an effect similar to an adaptation level is produced. With the withdrawal of the UCS the energizing effects of the two stimuli are now shown to be displaced above and below what would be a conditioned "signal" adaptation level as shown by the Between-Ss groups. The $80 \mathrm{~dB}$ tone has become more than a signal and has facilitatory effects, while the $40 \mathrm{~dB}$ tone now demonstrates inhibitory capabilities.

These results indicate that stimulus intensity dynamism in a repeated measures (Within-Ss) design is an increasing monotonic function during both acquisition and extinction. Furthermore, this has shown that many of Gray's restrictions against the use of GSR and extinction measures in the study of stimulus intensity are not applicable to the Within-Ss design, since significant results were obtained both during acquisition and extinction, using a GSR measure, with two transformations resulting in essentially the same behavioral results.

\section{References}

Beck, Sally B. Eyelid conditioning as a function of CS intensity, UCS intensity, and manifest anxiety scale score. J. exp. Psychol., 1963, 5, 429-438.

Darrow, C. W. The equation of the galvanic skin reflex curve: I. The dynamics of reaction in relation to excitation background. J. gen. Psychol., 1937, 16, 285-309.

Gray, J. A. Stimulus intensity dynamism. Psychol. Bull., 1965. $63,180-196$.

Grice, G. R., \& Hunter, J. J. Stimulus intensity effects depend upon the type of experimental design. Psychol. Rev., 1964, 4, 247-258.

Montagu, J. D., \& Coles, E. M. Mechanism and measurement of the galvanic skin response. Psychol. Bull., 1966, 65, 261-279.

\section{Note}

1. This research was supported by NIH training grant, MH 8526-02. 